\title{
Questões de gênero e geração na produção discursiva sobre envelhecimento nas três últimas décadas do século $\mathrm{XX}$
}

\begin{abstract}
Ana Maria Marques*
Um dos objetivos da minha pesquisa de doutorado era perceber como se construíam relações de gênero entre sujeitos envelhecidos ou em processo de envelhecimento nas últimas três décadas do século XX e como os discursos iam se construindo ao mesmo tempo. Os depoimentos colhidos compuseram um diálogo entre as fontes (jornais, revistas, monografias, leis e livros) e deram uma dimensão a essa construção discursiva por mim investigada, impossível de atingir o resultado final se dispensasse a História Oral.

As fontes orais, embora não fossem o objeto central de investigação, foram de fundamental importância para entender as redes, as relações e como se operavam os discursos naquele momento pesquisado. A análise dos depoimentos não deixou de considerar a subjetividade das fontes, assunto que tão bem aborda Alessandro Portelli (1996 e 2006). É importante levar em conta que os depoentes falaram de suas vivências passadas sem se despir de seus juízos de valores e de suas reflexões presentes sobre as posições que ocupam agora e as consequências das repercussões sobre seus depoimentos. Por isso, mesmo adotando um método de entrevista o resultado final era sempre diferente, porque o uso da fonte sempre passava pela "revisão" do depoente, que, por sua vez, limitava a utilização do depoimento por razões pessoais e, obviamente, subjetivas.
\end{abstract}

* Professora do Departamento de História da Universidade Federal do Mato Grosso (UFMT). 
É como sugere Danièle Voldman (2006): o historiador precisa “inventar as fontes" no sentido de sempre se perguntar como e a quem deve dirigir, como utilizar o que ouviu e, sobretudo, questionar para que servirá tais fontes constituídas sobre determinados processos.

O estudo dessas três décadas foi motivado pelas problematizações decorrentes, sobretudo, do crescimento da população idosa, no Brasil e no mundo, e também da incidência da questão de gênero, pois, afinal, as mulheres passaram a viver mais que os homens - logo, envelhecem mais do que eles. Em 1980, a expectativa de vida das mulheres era, em média, de 65 anos, enquanto a dos homens era de 57 a 58 anos de idade. Em 2000 , as mulheres aumentaram para 8,7 anos a diferença de expectativa de vida em relação aos homens. O fato de a Constituição de 1988 ter garantido aposentadoria compulsória aos idosos a partir dos 70 anos de idade, mesmo que não tivessem contribuído para a Seguridade Social, privilegiou as mulheres. Essas, segundo dados do IBGE de 2000, vivem em média nove anos a mais que os homens e se aposentam cinco anos antes por conta dos mecanismos de compensação, garantidos por lei, justificados em parte pelo custo da ausência no mercado de trabalho que as mulheres têm de arcar em seu período reprodutivo, mesmo que muitas não tenham filhos ou tenham tido menos filhos que as mulheres contabilizadas em 1980, segundo a demógrafa Ana Amélia Camarano (2003).

Nesse trabalho, o gênero é entendido conforme a definição de Joan Scott (1995, p. 86), como "um elemento constitutivo das relações sociais baseadas nas diferenças percebidas entre os sexos". Destaco, então, uma percepção sobre as relações de gênero entre idosos(as) motivadas pelo crescimento populacional dessa faixa etária, propiciado em parte pela melhoria nas condições de trabalho e os avanços científicos, sobretudo, da medicina. No Brasil, a partir da década de 1970, essa população sai da invisibilidade, passa pelo processo da cidadania, e chega a um discursivo do sujeito idoso "autônomo". Essa mudança do "velho", com toda carga pejorativa, passando para a "terceira idade" até chegar ao idoso, envolveu um investimento de alterações discursivas que deslocou e enredou poderes numa teia constituída por profissionais que falavam em nome da ciência do envelhecimento (geriatras e gerontólogos), das ciências para a "velhice sadia" (direito, áreas biológicas e do corpo) e dos próprios sujeitos que envelheciam, tomavam e transformavam os discursos conforme suas conveniências e contextos. 
As mulheres idosas passaram a constituir maioria arrasadora dos participantes de grupos de "terceira idade", herdeiras, de certa maneira, das redes de filantropia, assistencialismo e caridade religiosas. Os homens idosos ainda têm uma dinâmica política, voltados a associações de pensionistas, por exemplo. Mesmo fora do mercado de trabalho, eles ocupam espaços públicos nas reuniões de praça ou de bares. Suas histórias de vida constroem experiências divisórias nas relações de gênero e nas identidades geracionais. Nas palavras de Joan Scott (1999, p. 40, 48): a "identidade está amarrada a noções de experiência" e "não está confinada a uma ordem fixa de significados".

Marcelo Salgado foi, no Brasil, uma das vozes autorizadas a falar sobre o envelhecimento. Na década de 1970, ele trabalhou como assistente social do Serviço Social do Comércio de São Paulo (SESC-SP) e seus estudos gerontológicos foram reconhecidos por ampla comunidade intelectual brasileira. Em Santa Catarina mesmo, foi um dos primeiros intelectuais a discutir na academia as questões emergentes da gerontologia na década seguinte. Salgado, traçando um diagnóstico da situação do idoso no Brasil da década de 1970, escreveu que até então só existiam políticas assistenciais destinadas a instituições asilares, que por sua vez não davam conta da gama de problemas relacionados ao grupo etário envelhecido. Dentro desse contexto, ele denunciava:

[...] apesar dos permanentes esforços para redimensionar as formas de assistência ao idoso, no Brasil, ainda preponderam as instituições fechadas. Inspiradas no atendimento de urgência aos idosos dependentes, acolhem e prestam assistência a nível das necessidades mais diretas da subsistência. Este modelo, mais ou menos comum nas grandes cidades, reproduzido também para outras populações carentes, teve sempre grande apoio das instituições religiosas que, na grande maioria dos casos, foram as responsáveis pela sua implantação. A expansão rápida e nem sempre adequada desse tipo de recurso, se deve à gravidade da situação de um grande número de idosos abandonados a si mesmos, sem condições de por si só subsistir. O problema adquire novos aspectos porque, possivelmente à falta de outro meio, os idosos independentes têm buscado acolhida nas instituições fechadas (Salgado, 1982, p. 106-107). 
Marcelo Antônio Salgado representa uma geração que iniciou um movimento que objetivava dar visibilidade ao envelhecimento. Como ele, muitos envelheceram no curso das últimas três décadas. Ele mesmo, numa conferência proferida em 1999 (publicada na sessão de conferências do site do SESC-SP, acessada em julho de 2005), falando para participantes de grupos de terceira idade, evocava sua trajetória:

Costumo dizer, de um tempo para cá, que agora estou vivendo a minha problemática de DNA - Data de Nascimento Antiga. Quando comecei esse trabalho, há 30 anos, chegava nos ambientes da Terceira Idade e ouvia aquela referência: “Ah, Doutor Marcelo, um garoto". O tempo foi passando e de vez em quando eu ouvia outro tipo de observação: "Ah, o Marcelo ainda é jovem!" Agora já vão me perguntando: "Qual é mesmo o grupo a que o senhor pertence?" Ao longo desses 30 anos minha história também foi se formando e com ela a minha maturidade. Hoje, talvez eu esteja vivendo o tempo mais extraordinário da minha existência, que enfrento com naturalidade porque os senhores me ensinaram o significado do envelhecimento. Começo a viver a adolescência da minha envelhescência, porque também estou entrando na Terceira Idade. Espero entrar nela com um pouco mais de segurança, com maiores objetivos existenciais, que foram incorporados ao longo de 30 anos, observando o envelhecimento de cada um dos senhores; e as atitudes que cada um teve sempre em relação aos problemas, às dificuldades, e a nobreza com a qual cada um tem vivido o seu próprio envelhecimento.

A reflexão sobre as reivindicações, das quais muitas foram transformadas em políticas públicas, não só colocou o envelhecimento populacional na pauta das preocupações mundiais, como provocou uma mudança de posturas. Problemático envelhecer? Sim, sempre foi de certa forma pelos fatores do desgaste físico, afinal, parafraseando Minois (1999), desde a Pré-História envelhecer não era tarefa fácil, pois poucos são os fragmentos de esqueletos encontrados de pessoas que ultrapassavam os 30 anos.

Quando iniciei meus contatos com as várias pessoas que são fontes e referências nesta minha pesquisa, algumas citaram Marcelo Salgado. 
Neusa Guedes, a primeira pessoa a mobilizar a criação do Núcleo de Estudos da Terceira Idade (NETI), na Universidade Federal de Santa Catarina (UFSC), quando me concedeu entrevista, contou-me que ele fora convidado a presidir um debate pioneiro para a época dentro da universidade. Selma Junkes, coordenadora de grupos no SESC-SC, também, ao me indicar vários nomes de pessoas "interessantes" para conversar sobre minha pesquisa - que representavam referências para as organizações dos grupos que se formavam, passou-me o endereço de correio eletrônico de Marcelo Salgado. Ele me respondeu prontamente e, através do SESC-SP, foi-me enviado um volume da biblioteca de lá: uma obra de sua autoria, editada inicialmente em 1980 (recebi a segunda edição, de 1982). Nessa obra, que considero também um documento de época, entre os 16 autores elencados na bibliografia há predominância de referências francesas e de clássicos, como: Freud, Simone de Beauvoir e Claudine Attias-Donfut. Entre os dois autores nacionais referenciados, um deles é o próprio Salgado. O que nos faz pensar que não existia uma literatura nacional significativa que discutisse o tema do envelhecimento, suas questões subjetivas e das gerações.

Não existiam inventários quantitativos, muitos idosos não sabiam de seus direitos. $\mathrm{Na}$ área rural, por exemplo, profissionais colocados em contato com essa população, ou políticos interessados no voto, faziam um trabalho de facilitação aos acessos beneficiários (aposentadorias, pensões e atendimento médico, principalmente). A Prof. ${ }^{a}$ Neusa Guedes conta (em entrevista concedida em 7 de março de 2003) sua experiência nessa época:

Chegou 75, surgiu um programa dentro do INPS que se chamou de assistência direta e indireta a pessoas mais velhas, idosas [...] A assistência direta seria feita através de grupos de pessoas idosas, que se reuniam uma vez por semana, e o INPS dava uma ajuda supletiva para se comprar lanches, para se comprar material para se fazer artesanato, ou seja, se subentendia que o idoso era alguém carente economicamente. Assim nasceu o programa, lá dentro do INPS. A assistência indireta era feita através de convênios com asilos, casas de repouso que precisariam ser classificadas. Então ia lá uma assistente social, um médico e uma funcionária administrativa ver as condições desses lares, desses asilos, porque 
se queria ou se estimava ou era meta não se fazer convênio com depósito de velhos e sim com instituições que dessem realmente uma assistência digna a pessoas idosas. Assim era previsto que o asilo tivesse uma equipe de fisioterapeuta, terapeuta ocupacional, enfermeiro, etc. - tudo aquilo que o idoso precisasse no seu envelhecimento biológico, psicológico e social. Só que naquela época, não existia, aqui na nossa realidade nem em quase todo Brasil, fisioterapeuta e terapeuta ocupacional - isso era coisa que ninguém imaginava que viesse a se tornar real. Então impediu de a gente fazer convênio - isso enquanto eu era assistente social do INPS.

A professora, no seu depoimento, denunciava um tipo de concepção assistencialista da época, cuja mentalidade era suprir as necessidades básicas (saúde e alimentação) e de ocupação (com o artesanato). Ao mesmo tempo, foi esse trabalho assistencialista que permitiu a faceta de seus reveses: as denúncias, as reivindicações - a visibilidade.

Os "velhinhos" comemoraram a Semana do Idoso saindo das instituições, foram festejar no recém-inaugurado calçadão da Rua Felipe Schmidt, no Centro de Florianópolis, que se tornou o "palco da saudade" - era o que dizia o jornal catarinense O Estado, de 24/09/1977, em manchete de primeira página. Uma foto estampava a primeira página do referido jornal. No interior dele, uma página inteira tratava do evento promovido pelo Centro de Serviço Social do INPS junto das entidades que exerciam atividades ligadas aos idosos. Vale destacar a participação de um grupo, novo naquele momento, o "Continuação da Vida".

Em entrevista, Neusa Guedes contou-me que muitos na época acharam graça e até acusaram as assistentes sociais e voluntárias de ridicularizarem as velhinhas, fazendo-as passar por papéis de criança. Se o calçadão virou um palco e ali todas estavam encenando, vale lembrar que "a vida imita a arte". Dona Neusa, dizia-me, como que em tom de defesa, que se tinha sido a dança "o teatro", era porque ao serem perguntadas sobre o que queriam escolher para se divertir, elas escolheram fazer um baile, pois era o divertimento delas quando moças. E algumas pelo menos, capricharam na produção, com colares de pérolas (tudo aqui se torna verdadeiro) e chapéu. As bolsas não tiveram onde colocar, e dançaram com elas a tiracolo. Dançavam entre elas formando pares, não importava a falta de homens. Uma multidão não dançava, mas lhes assistia. 
Durante a década de 1970 houve, em Florianópolis, uma mobilização para construir o Lar São Francisco. A Ordem Terceira de São Francisco, com sua fraternidade há mais de dois séculos na capital catarinense, estava preocupada com seus integrantes em idade avançada e conseguiu mobilizar forte campanha entre a comunidade objetivando a construção de um lar para idosos que pretendia ser modelar à época. Dona Helena Borba $^{1}$ foi uma das pessoas que tomaram a frente nesse projeto. Ela conta que, na época, existiam "irmãos idosos" em outras instituições não católicas e havia uma preocupação a respeito do acompanhamento espiritual direcionado a esses e outros que futuramente precisassem ser asilados, pois a orientação de outras religiões não católicas nem sempre era aceita. Levantado esse "problema" inicial, a ideia foi levada ao então assistente espiritual, Frei Junípero: "Nós poderíamos fazer uma casa para nós, o senhor aceitaria?", teria dito Dona Helena, que relata incluindo-se na primeira pessoa do plural (os irmãos da Ordem Franciscana). O frei teria respondido positivamente, em 1974, e titubeou dois anos depois, após muitas atividades para angariar fundos, quando a construção começou: "Se soubesse que era assim tão grande, não teria me metido". Ao que Dona Helena rebateu: "Agora já se meteu".

Dona Helena conta que seu marido acompanhou as obras de perto e que se propôs a fazê-lo se fosse para construir algo que pudesse proporcionar uma velhice como ele gostaria para si. Defendia que o projeto deveria contemplar suítes individuais integradas a um espaço comum (refeitório, biblioteca, capela). Essa concepção foi discutida com o engenheiro que elaborou o projeto: um eslavo, cujo nome não foi possível transcrever da entrevista, que trouxera seus conhecimentos arquitetônicos adquiridos com sua experiência em visita a "casas de idosos" na Alemanha. "Então, ele fez a nossa casa naqueles moldes que ele havia visto, foi toda feita para idosos, não tem degraus, tem corrimãos, tudo como ele

1 Conheci Dona Helena em setembro de 2005. Visitei-a em sua casa, no Centro da cidade, onde ela vive com nora, netos e agregados da família (seu marido e filhos são falecidos). Ela me recebeu muito gentilmente e disse que já teria contado "tudo" para as acadêmicas que a entrevistaram em 1997. Então, emprestou-me um exemplar da monografia que publicou a entrevista que me serve de fonte de citação e, de certa forma, confirmação e correção de algumas falas possibilitadas através desse contato direto. Segue a referência: HELDWEIN, Amélia Maria Lobo; VILAIN, Veraldina. Diagnóstico e proposta de capacitação de cuidadores de idosos institucionalizados na área do relacionamento interpessoal. Monografia (Especialização em Gerontologia) - Universidade Federal de Santa Catarina, Florianópolis, 1997. p. $67-74$ 
viu". A planta teria sido discutida também considerando sugestões de Terezinha Rovaris, citada por Dona Helena como alguém "do INPS". Os vários personagens envolvidos na história da construção do Lar São Francisco mostram a diversidade de forças e a complexidade de interesses que agregam concepções de época, interesses individuais e de grupos.

A primeira iniciativa de Dona Helena para alavancar a construção do Lar foi rifar uma almofada confeccionada por ela, em 1974. Daquele momento em diante, segundo ela, muitas outras mulheres se mobilizaram fazendo pequenas doações, trabalhando voluntariamente em festas e vendas de produtos, ou mesmo influenciando maridos e parentes a fazerem as "grandes" doações em dinheiro ou em posses. O então governador Antônio Carlos Konder Reis fez um repasse de 100 mil cruzeiros para a aquisição do terreno, dinheiro que foi utilizado na compra de material de construção, pois o terreno no Alto Ribeirão da Ilha foi doado por Francelino Cordeiro, esposo de Maurina Vieira Cordeiro, que muito ajudou trabalhando voluntariamente. Francelino administrava uma granja e doou muitas galinhas para a Feira do Amor ao Próximo. Essa feira era organizada todos os anos na Baía Sul, no Centro de Florianópolis, por incentivo do governo estadual. A então irmã do governador, Maria Pompeia Konder Reis Malburg, era quem fazia a coordenação. As instituições eram convidadas a participar montando sua barraca, e o que vendessem e arrecadassem revertia em benefício das instituições que representavam. A barraca da galinha, organizada pelas irmãs da Ordem Terceira, era naquele ano de 1975 em prol do projeto do Lar São Francisco. No depoimento de Dona Helena, aos 90 anos completados em 2005, ela dizia que o que importava era o reconhecimento divino. Muitas mulheres, como Dona Helena, nem faziam questão de reconhecimento, como se a invisibilidade fosse natural a elas; outras ganhavam reconhecimento depois de falecidas, com seus nomes nas fachadas de prédios públicos, tabuletas de ruas etc.

A inauguração do Lar São Francisco aconteceu em 25 de novembro de 1980, dia de Santa Catarina. Era para ser no dia de São Francisco, 4 de outubro, mas Dona Helena estava de luto pelo seu único filho morto em um acidente de avião. Nota-se o respeito e a importância dessa mulher nessa empreitada, tanto que a inauguração foi adiada. A edificação foi erigida em formato de "U", com 46 quartos individuais com banheiro, refeitório comum, sala de estar, salinha de televisão e outra de atividades manuais, cozinha e copa, dependências administrativas e a enfermaria, 
que foi construída depois da inauguração do Lar, bem como a Casa de Orações. Foi para a época, um projeto arrojado e inovador, diferente dos projetos tradicionais dos asilos antigos que seguiam a mesma lógica das instituições disciplinares, prisões e colégios, cuja arquitetura separava homens de mulheres em alas (compostas por grandes quartos ou salas coletivas), todas as portas voltadas para o interior e somente a porta da recepção abria-se ao "mundo externo". O modelo das instituições disciplinares vem do final do século XIX, como diz Foucault (2003), quando a própria arquitetura revelava um tipo de poder que permitia a substituição da punição pelo controle.

Contemporâneo à construção do Lar São Francisco, no Ribeirão da Ilha de Santa Catarina, foi o Centro Vivencial para pessoas idosas, no Itacorubi, sob o empenho da Igreja Metodista. O Pastor Willian Schisler Filho dirigiu a empreitada a convite do seu então bispo de província que por sua vez havia recebido proposta da Sra. Gama D’Eça (representando um grupo de mulheres que se confraternizavam frequentemente em torno de um lanche em sua casa) para construir em Florianópolis uma casa para idosos. O referido bispo fez contato com o Pastor Schisler, gaúcho de Uruguaiana que vivenciara nos Estados Unidos uma experiência com lares para idosos ${ }^{2}$.

Não que eu queira dizer que a velhice não assombra o imaginário das pessoas, homens (pelo medo da impotência, da perda da virilidade que tanto marca a cultura da masculinidade) e mulheres (pela perda de um referencial de beleza jovem e fértil que está presente no estereótipo da feminilidade), mas eu diria que as várias mobilizações que ocorreram a partir da década de 1970 conferiram positividades à velhice, que antes não eram visibilizadas ou não tinham força discursiva. Envelhecer, a partir daí, simbolizava romper com um rótulo criado historicamente e que havia conferido invisibilidade a idosos(as).

O NETI foi implantado junto à comunidade acadêmica em 1982, como um programa de extensão da UFSC. Segundo depoimento da Prof ${ }^{a}$ Neusa Guedes, o NETI surgiu da necessidade premente percebida através

2 Esta história me foi contada informalmente, pela viúva do pastor, Sra. Edith Long Schisler, no dia $1^{\circ}$ de setembro de 2005. Dona Edith recebeu-me gentilmente em sua casa para um chá. Ela é americana de nascimento, sua mãe é brasileira, conheceu o pastor nos EUA. Ela acompanhou toda a trajetória da implantação do Centro Vivencial até o falecimento do pastor há dez anos. Depois, ela mesma assumiu a diretoria da casa até 2003 . 
de um questionário lançado a funcionários aposentados da universidade, sobre suas demandas, e com o passar dos anos tornou-se uma referência em nível nacional para outras universidades que, por sua vez, adotaram programas similares. O jornal O Estado, de 28/09/1983, confirmava que a criação do NETI era uma "iniciativa pioneira a nível universitário e partiu da coordenação das professoras Neusa Guedes, do Departamento de Serviço Social e Lúcia Takase Gonçalves, de Enfermagem”. Os encontros desse Núcleo aconteciam todas as quartas-feiras à tarde, na antiga igrejinha da Trindade (que, atualmente, compõe o patrimônio da UFSC e é um espaço cultural: Teatro da Igrejinha). Completava o artigo do mesmo jornal:

[...] os debates são coordenados pelos próprios idosos, que sugerem o tema que querem abordar. Do núcleo participam duas professoras e quatro estagiárias do Serviço Social. As reuniões semanais do grupo de idosos [...] são abertas a todos que se interessam no debate e discussões sobre alternativas e participação comunitária do idoso.

No entanto, o NETI enfrentou uma série de entraves para se estabelecer e ser reconhecido como algo importante. Foi o trabalho insistente destas "agentes sociais" que resultou nesta "participação comunitária". A Prof ${ }^{a}$ Neusa Guedes (1997, p. 27-28) recorda o que para ela foram "fatos pitorescos" no decorrer dos primeiros anos de instalação do núcleo, e entre estes cita uma pesquisa realizada entre familiares e técnicos da comunidade universitária que se declararam contrários a uma "Escola para Idosos" e a negativa dos próprios funcionários e professores universitários em participar de reuniões, cujo tema versasse sobre questões da aposentadoria. A velhice estava definitivamente sendo colocada como problema.

Em Santa Catarina, a cidade de Joinville sempre se destacou na dança e também na modalidade sênior. Quando entrevistei Marília Fragoso (aos 17/05/2005), ela confirmou esse pioneirismo da dança sênior de Joinville e contou sua experiência de trazer a modalidade para os idosos agregados por ela, a partir do trabalho iniciado com aposentados (a empresa para a qual ela trabalhava como assistente social, a CELESC, de Capoeiras-Florianópolis, na época, teria pedido que ela se dedicasse a um trabalho voltado para aquilo que fosse mais preocupante na comunidade - hoje em dia se fala em "responsabilidade social". Marília conta sua 
experiência de ter trazido a dança sênior para Florianópolis e seu engajamento com as entidades emergentes:

Fiz uma visita a Joinville enquanto presidente do Conselho Estadual do Idoso, e conheci a dança sênior. Quem me apresentou foi a Matilde, que era uma assistente social. Vim pra Florianópolis e resolvi organizar um grupo de dança sênior. Através da ANG trouxemos a Matilde como professora, algumas colegas minhas da Secretaria da Saúde e professores de Educação Física. Resgatei pessoal conhecido que se interessou e fizemos o primeiro grupo de dança sênior. Dali eu comecei a trabalhar a dança sênior com as esposas dos aposentados. Não foi simples inicialmente, porque eu só tinha a fita de vídeo, o livrinho e um curso. Foi com muito sacrifício. Eu tentando dar os passos em casa, porque no dia seguinte ia aplicar. Mas consegui trabalhar a dança sênior com eles. Aí resolvi fazer um segundo curso. Mais algumas colegas fizeram e eu já levei o grupo dessas senhoras que estava aplicando. Aí eu filmei. Sendo filmado ficou mais fácil. A dança sênior trabalha um monte de coisas: o afeto, o toque, o carinho, a auto-estima, questão da saúde. Tínhamos esposas de aposentados que diziam: "Marilia, estou parando de tomar remédio, me sinto tão bem e espero segunda-feira com ansiedade". Porque era uma dança alegre e todas as segundas-feiras a gente dançava. Tentei levar os homens também para participarem, mas não aceitavam. Blumenau, Joinville, os homens dançam com mais naturalidade.

Sobre a "naturalidade" de aderirem à dança entre os teuto-brasileiros, podemos inferir que incide aí o fator cultural que diferencia teutos de luso-brasileiros. Não que um seja mais afeito à música que o outro, mas o tipo de música e os estilos é que diferem os gostos e as práticas. $\mathrm{Na}$ entrevista que realizei com Olga Schmitt ${ }^{3}$, ela contara sua experiência como

3 Entrevista com a Sra. Olga Schmitt, aos 21/8/2003. Na data, ela tinha 83 anos de idade. Dona Olga é avó materna de Cristina Scheibe Wolff, minha orientadora de doutorado. Entrevistei-a porque consideramos interessante a experiência dela como elemento nesse entorno cultural e contextual que a pesquisa aborda. A depoente é herdeira de especial erudição, pois seu pai foi escrivão e oficial de justiça, teve uma prole de oito filhos, dos quais só um homem. O pai, então, teve a preocupação de que ela estudasse, até mesmo para ajudá-lo no tabelionato. Dona Olga, assim, diferente da maioria das moças de sua época, teve oportunidade de estudar, frequentou colégio evangélico e grupo escolar, onde pôde se aperfeiçoar no conhecimento da língua alemã e portuguesa. 
participante de um grupo de idosos marcado pela cultura teuto-brasileira de Panambi, no Rio Grande do Sul:

Nós formamos um grupo partindo de uma sociedade que tem lá. Nós temos ali umas oitenta a cem. Mas não são só idosos, tem gente de sessenta, menos até algumas, principalmente que estão sozinhas: viúvas, separadas ou solteiras. Tem mais ou menos uns vinte casais que participam do nosso grupo. Nós somos um grupo fechado, pagamos nossa anuidade e fazemos nossos programas: passeios, viagens, excursões, jantar, essas coisas. Temos reuniões de quinze em quinze dias, às vezes também temos convite pra outros lugares. O principal, o que todo mundo quer, é baile, dançar, dançar mesmo, e como não tem muito homem, é mulher com mulher, não tem problema nenhum, dançam, conversam, brincam. Eu gosto muito de dançar. Meu marido não era muito dançarino, mas eu de casa sou de família que gostava, meu pai dançava muito bem. Meu marido era forçado que ele fazia. Nesse ponto eu recupero. Tem um que outro senhor que é amigo de infância, que às vezes vem dançar com a gente, mas tudo assim na melhor brincadeira, não representa que há nenhuma traição entre os casais ou nenhuma malícia. No nosso grupo não tem solteiro, nem viúvo. $\mathrm{Na}$ nossa cidade, uma cidade pequena ainda, se conhece quase tudo, me lembro assim, dois, três viúvos, quando tem. Não tem. E solteirão, também, difícil.

A experiência de Dona Olga confirma os dados do crescimento demográfico que indica o aumento da proporção de mulheres envelhecidas em relação aos homens. A questão do gênero é preocupante no sentido quantitativo, mas também o fator comportamental que, presente na mesma fala, revela o recato, o cuidado e as limitações que atingiram a vida conjugal de mulheres dessa geração. Dona Olga pode ser vista também como representante de uma cultura de ascendência alemã e confirma o gosto pelas danças de salão.

Nas monografias do curso de Gerontologia que pesquisei no acervo do NETI, era recorrente a inferência às proposições à "velhice bem sucedida". Esse perfil de velhice, no entanto, não incluía o fato de que os idosos, especialmente septuagenários ou octogenários, dificilmente o 
alcançariam, haja vista as diversas doenças que atingem essa faixa etária. Por isso, muitos desses trabalhos recaem na problemática que, especialmente, a gerontologia criou, ao valorizar uma certa juventude (saúde física, bem-estar, etc.), nas suas propostas de combate à deteriorização e àdemência - um risco, como foi apontado por Guita Debert (2004, p. 15):

A nova imagem do idoso não oferece instrumentos capazes de enfrentar a decadência de habilidades cognitivas e controles físicos e emocionais que são fundamentais, na nossa sociedade, para que o indivíduo seja reconhecido como um ser autônomo, capaz de um exercício pleno dos direitos de cidadania. A dissolução desses problemas nas representações gratificantes da terceira idade é um elemento ativo na reprivatização do envelhecimento, na medida em que a visibilidade conquistada pelas experiências inovadoras e bem-sucedidas fecha o espaço para as situações de abandono e dependência.

No que diz respeito às políticas públicas, a Lei Orgânica da Assistência Social (LOAS - Lei 8.742/93) estabelece que cabe ao governo federal a prerrogativa de elaboração de normas gerais da política de assistência social, garantindo seu financiamento e a execução de programas, projetos e serviços de enfrentamento à pobreza. A lei prevê formas de articulação entre Estado e sociedade civil através dos Conselhos.

O Sr. Marcos Wandresen (entrevistado dia 10 de maio de 2005), que já foi membro do Conselho Estadual do Idoso, em Santa Catarina, contou do papel desses Conselhos:

O Conselho deve formular as políticas, deve acolher e fazer o registro das instituições legalmente constituídas para atender o idoso e dirimir as dúvidas neste processo todo, pois não é apenas um conselho consultivo, mas é um conselho formador das políticas e é o que vai ajudar e apoiar todo o desenvolvimento da organização de programas, segundo o regime de atendimento. Veja que o registro da entidade é uma condição para o seu funcionamento. Hoje se tem um princípio de municipalização do atendimento e uma política de coordenação estadual e tem a coordenação nacional, através do Conselho Nacional. 
Os Conselhos, nos diferentes níveis (municipal, estadual e nacional) funcionam como representantes dessa sociedade civil, que pode encontrar neles um apoio à efetivação do que está colocado no texto da lei. Nos grupos, nas associações, as pessoas escutam os ecos do que elas têm direito, descobrem que têm direitos, por vezes, ou são envolvidas numa rede discursiva que as coloca nesse entorno reivindicatório. As leis, ao mesmo tempo que garantem a integração dos sujeitos no grande projeto de cidadania que inclui "todos", revelam os dilemas de uma sociedade de desigualdades constituída pelas exclusões de gênero, classe e geração.

As políticas, com seus aparatos legais, e a gerontologia com toda a produção acadêmica que mobiliza a formação de profissões (novas, inclusive), trazem à tona uma rede discursiva que cria a noção de sujeito autônomo - aquele que não precisa (ou só em casos extremos precisará) das instituições asilares (fechadas). A rede discursiva que constitui os sujeitos coloca o poder no plural. Como diz Foucault (1995, p. 247):

As relações de poder se enraízam no conjunto da rede social. Isto não significa, contudo, que haja um princípio de poder, primeiro e fundamental, que domina o menor elemento da sociedade; mas que há, a partir desta possibilidade de ação sobre a ação dos outros (que é co-extensiva a toda relação social), múltiplas formas de disparidade individual, de objetivos, de determinada aplicação de poder sobre nós mesmos e sobre os outros [..]. As formas e os lugares de "governo" dos homens uns pelos outros são múltiplos numa sociedade: superpõem-se, entrecruzam-se, limitam-se e anulam-se, em certos casos, e reforçam-se em outros.

Os espaços dos grupos de "terceira idade" muito contribuíram para questionar os próprios espaços convencionados às pessoas envelhecidas. Mulheres romperam o estereótipo da "vovó" - aquela que continuaria sua responsabilidade doméstica na função de cuidar dos netos. Elas foram para os grupos de idosos(as), lugares de encorajamento também, e de lá para os bailes, as viagens, os estudos, os cuidados com a aparência física, etc. Homens se inquietaram - os espaços públicos deixaram de ser deles por excelência.

Esse estereótipo do homem - do público, viril e que detém o poder - vem sendo desconstruído. Segundo Sócrates Nolasco (1995, p. 19): “[...] 
não se acredita mais que exista o masculino como único conceito norteador e gerador de referências para o comportamento dos indivíduos". Ele acrescenta:

As exigências viris, de posse e poder, bem como ser assertivo e competitivo sexualmente, mantêm os homens presos à questão do desempenho. Os padrões de comportamento que os qualificam como homens se aproximam dos exigidos para máquinas. Enquanto identificados como homem máquina, estes indivíduos ficam impossibilitados de problematizar a maneira como socialmente tornaram-se homens (Nolasco, 1995, p. 21).

Os homens envelhecidos foram confrontados com esse estereótipo. É difícil para eles, na maquinaria que os produziu, darem-se conta de que a idade pode abalar a virilidade e que o poder, advindo em parte da força produtiva do trabalho, está enfraquecido, muitos já não são mais provedores. Esse é o momento de problematizar sua masculinidade, e é na relação com o feminino que as reações em defesa do homem estereotipado emergem. Não querer participar dos grupos de "terceira idade", ou concordar que as mulheres que frequentam esses grupos são "velhas assanhadas" são formas de defesa e de conformação ao padrão estereotipado do macho. Raquel Soihet (2005, p. 609) já dissera que a zombaria, o deboche, a ridicularização de movimentos em prol de mudanças com relação aos papéis de gênero, configuram-se como representações com vistas à conservação do status quo. Entretanto, a partir do momento em que as esposas ou mulheres de seu convívio saem do espaço doméstico, mesmo com as resistências, e voltam transformadas pelo efeito que o baile e a convivência no grupo estimulam, também modificam outros comportamento e modos de pensar. Se não são seduzidos, são induzidos a assumir posturas, dividir tarefas domésticas ou do próprio cuidado de si, pois as mulheres estão, geralmente à frente, operando mudanças.

Essa chamada "liberdade geracional" foi muito bem questionada por Alda Motta (2000), no que diz respeito à importância de estarmos atentos para a ambiguidade do sentido dessa liberação que estaria escamoteando a percepção de toda uma gama de preconceitos sociais ainda vigentes em relação aos velhos e às mulheres. De um lado as mulheres tornam-se livres na velhice porque estão desresponsabilizadas do cuida- 
do da prole e, por outro, estão liberadas porque as convenções que lhes atribuíram um "lugar da mulher" (eminentemente o espaço doméstico) foram criadas levando em consideração a vida reprodutiva. De certa forma, as mulheres envelhecidas podem sair de casa porque estão fora do "mercado" competitivo das relações amorosas heterossexuais, que colocou o comportamento da mulher como depositário da honra do homem. Levando em conta o pressuposto apresentado por Miguel Vale de Almeida, que considera a masculinidade como continuamente construída, enquanto a feminilidade é essencializada e "naturalmente" reafirmada nas gravidezes e partos, podemos inferir que exista um entendimento de que na velhice aconteça uma perda de feminilidade. Talvez nas relações sociais, as mulheres idosas tenham essa liberação das obrigações colocadas às mulheres mais jovens: o recato que protege a si, a prole e a família lhes confere uma reputação, diferente dos homens, que na contrapartida têm sua fama fortemente marcada no público. Numa concepção de "masculinidade hegemônica"4 , os homens podem sair mais e podem se relacionar sexualmente com mais mulheres, porque isso é uma marca da referência à virilidade, por exemplo. Essa concepção é, no entanto, também opressora, pois não admite que homens possam ser sensíveis e afetuosos sem serem afeminados, e cobra um perfil de garanhões prontos para o ato sexual como se fosse algo meramente instintivo ao homem (animal macho).

Em boa parte dos bailes organizados nos espaços de reunião de grupos de "terceira idade", as mulheres dançam entre si e a sedução não é a tônica dessa atividade e sim a alegria, o reviver os tempos de juventude, que obviamente, também remetem às expressões do corpo. Se existia uma idade para a sedução e para expressão da sexualidade, essa geração de homens e mulheres idosos(as) das últimas décadas a questionaram e provaram nos seus comportamentos que não, mesmo que estejamos ainda sob um suposto paradigma de comportamentos de gênero e geração.

4 Almeida assim conceitua: "A masculinidade hegemônica é um modelo cultural ideal que, não sendo atingível por praticamente nenhum homem, exerce sobre todos os homens um efeito controlador, através da incorporação, da ritualização das práticas da sociabilidade quotidiana e de uma discursividade que exclui todo um campo emotivo considerado feminino; e que a masculinidade não é simétrica da feminilidade, na medida em que as duas se relacionam de forma assimétrica, por vezes hierárquica e desigual. A masculinidade é um processo construído, frágil, vigiado, como forma de ascendência social que pretende ser" (ALMEIDA, 1995. p. 17). 
As senhoras Neusa, Olga, Helena, Marilia e Edith, e o Sr. Marcos foram pessoas e fontes imprescindíveis para a realização deste artigo. Cada um com sua subjetividade, a sua maneira de reagir e resistir a falar de suas próprias experiências. A narrativa de fatos vividos na década de 1970, 1980 ou 1990 vinham em suas memórias recheadas de emoções do passado e reelaboradas com as reflexões do tempo que passou. As fontes orais são, como diz Alessandro Portelli (1996, p. 70), "campo de possibilidades expressivas". Portanto, não foi com a intenção de capturar um fato vivido, objetivamente, que os entrevistei, mas sim para realçar a subjetividade dos fatos e das fontes capazes de tornar valorosos os acontecimentos e, em especial aqui, as redes discursivas sobre envelhecimento.

\section{Referências bibliográficas}

ALMEIDA, Miguel Vale de. Senhores de si: Uma interpretação antropológica da masculinidade. Lisboa: Ed. Fim de Século, 1995.

CAMARANO, Ana Amélia. Mulher idosa: suporte familiar ou agente de mudança? Revista Estudos Avançados. São Paulo, v. 17, n. 49, set./dez. 2003.

DEBERT, Guita G. A reinvenção da velhice. São Paulo: Edusp/Fapesp, 2004.

FOUCAULT, Michel. O Sujeito e o Poder. In: DREYFUS, Hubert L.; RABINOW, Paul. Michel Foucault: uma trajetória filosófica para além do estruturalismo e da hermenêutica. Rio de Janeiro: Forense Universitária, 1995.

A verdade e as formas jurídicas. 3. ed. Rio de Janeiro: NAU Editora, 2003.

GUEDES, Neusa. "A construção de um caminho (Resgate histórico: tropeços e passos a caminho de acertos)". In: GRÜNEWALD, Virgínia (org.). NETI: A construção de um caminho na Gerontologia. Florianópolis: Editora Copyflo, 1997.

MINOIS, Georges. História da velbice no Ocidente: da Antiguidade ao Renascimento. Lisboa: Teorema, 1999.

MOTTA, Alda Britto da. Gênero e geração: de articulação fundante a "mistura indigesta". Trabalho apresentado no VI Simpósio Baiano de Pesquisadoras sobre Mulheres e Relações de Gênero, 2000.

NOLASCO, Sócrates. A desconstrução do masculino: uma contribuição crítica à análise de gênero. In: NOLASCO, Sócrates (org.). A desconstrução do masculino. Rio de Janeiro: Rocco, 1995.

PORTELLI, Alessandro. A filosofia e os fatos. Revista Tempo. Rio de Janeiro, v. 1. n. 2, dez. 1996. 
. O massacre de Civitella Val di Chiana (Toscana: 29 de junho de 1944): mito, política, luto e senso comum. In: FERREIRA, Marieta de M.; AMADO, Janaína (org.). Usos \& abusos da História Oral. 8. ed. Rio de Janeiro: Editora FGV, 2006.

SALGADO, Marcelo. Velhice, uma nova questão social. 2. ed. São Paulo: SESC-CETI, 1982. Biblioteca Científica. Série Terceira Idade.

SCOTT, Joan. Gênero: uma categoria útil de análise histórica. Revista Educação e Realidade. Porto Alegre, v. 20, n. 2, jul/dez. 1995.

Experiência. In: SILVA, A.; LAGO, Mara C. de S.; Ramos, T. (org.) Falas de gênero. Florianópolis: Ed. Mulheres, 1999.

SOIHET, Raquel. Zombaria como arma antifeminista: instrumento conservador entre libertários. Revista de Estudos Feministas. Florianópolis, v. 13. n. 3, 2005.

VOLDMAN, Danièle. A invenção do depoimento oral. In: FERREIRA, Marieta de M.; AMADO, Janaína (org). Usos \& abusos da História Oral. 8. ed. Rio de Janeiro: Editora FGV, 2006.

Resumo: O presente artigo mostra, através de fontes orais e escritas, como se criaram redes discursivas sobre envelhecimento nas três últimas décadas do século XX. O movimento de três décadas, que retira velhos(as) da invisibilidade, passando pelos vários eufemismos da velhice, até chegar ao idoso ativo e saudável, passou por uma série de construções envolvendo políticas públicas, associações, legalizações, produções acadêmicas e interesses econômicos, bem como o próprio envelhecimento populacional. Ainda, mulheres vivem mais que os homens e as experiências revelam diferentes relações que constituem os gêneros na velhice.

Palavras-chave: envelhecimento; gênero; fontes orais.

Problems of gender and generation in the production of discourse on aging in the last three decades of the twentieth century

Abstract: This article shows, through oral and written sources, but also by networks discourse on aging in the last three decades of the twentieth century. The movement of three decades of invisibility removes old, through the various euphemisms for old age until the elderly healthy and active, went through a series of buildings involving public policy, associations, legalization, academic productions and economic interests as well as the aging population. Also, women live longer than men and experience show different relationships that are the genres in old age.

Keywords: aging; gender; oral sources. 